International Journal of Social Science And Human Research

ISSN(print): 2644-0679, ISSN(online): 2644-0695

Volume 04 Issue 12 December 2021

DOI: $10.47191 /$ ijsshr/v4-i12-18, Impact factor-5.586

Page No: $3584-3600$

\title{
Change Laboratory Workshops as Tools for Improving Learner Leadership in Schools: A Researcher-Interventionist Approach
}

\author{
Selma Ndeyapo Kandjengo ${ }^{1}$, Elock Emvula Shikalepo ${ }^{2}$ \\ ${ }^{1}$ Senior Education Officer: Directorate of Adult Education Ministry of Education, Arts and Culture, Namibia \\ ${ }^{2}$ Lecturer: Faculty of Education the International University of Management, Namibia
}

\begin{abstract}
The purpose of this study was to engage learners and teachers with the aim of developing leadership potential and improving the leadership capacity and capabilities of the learner leaders through mainly Change Laboratory Workshops, which were conducted with the Learner Representative Council (LRC) members, at a public secondary school in the Oshana Region, Namibia. The study was guided by the following main question: How can learner leadership structure be improved in schools? The researchers used a researcher-interventionist approach to implement measures for improving learner leadership, guided by the ideals of the Cultural Historical Activity Theory (CHAT), as a theoretical lens through which the researchers made interventions for improving learner leadership at school. Empirically, the study made use of a qualitative research methodology carried out through a case study design. The population consisted of teachers and learners of the case study school. The data was collected by questionnaires, interviews, document analysis, observation and journaling. The data was analysed thematically, interpreted and discussed inductively.

Key findings reveals that even though the concept of learner leadership was familiar within the school environment, the concept was not optimally applied, which necessitated intervention for correct application and positive results. Change Laboratory workshops provided ideal opportunities through which learner leaders were engaged to map out the challenges they were faced with and advancing policy proposals for improvement. Learner leaders were open to reveal the support they were not receiving from teachers and appealed on teachers to provide much needed support. This is in addition to a need for teachers to make follow-ups on matters reported to them by learner leaders in order to instill confidence and trust among learner leaders. It is recommended that researchers in the field of leadership especially with focus on young leaders should always model their research on researcherinterventionist approach in order to help improve the quality of young leaders in schools.
\end{abstract}

KEYWORDS: Learner leadership, Learner representative council, Leadership, Management, learner voice, learner leader, Cultural Historical Activity Theory (CHAT), Change Laboratory Workshop (CLW), Researcher-Interventionist Approach

\section{BACKGROUND OF THE STUDY}

The contemporary concept of learner voice is described by as an "apparent desire to encourage young people to articulate their concerns and aspirations about a whole range of matters that has the potential to offer an important contribution to education" (Fielding, 2004. p. 197). Similarly, Mitra (2007) and Mitra and Gross (2009) describe learner voice as the many ways in which youth could actively participate in school decisions that will shape their lives and the lives of their peers. In a similar vein, Grant (2015) states that student voice explains the diversities of ways in which learners can share in decision-making in schools. The essence of learner voice is the unleashing of learners 'potential in multiple facets, including learning, recreation and leadership.

Current views on learner voice are described by Mitra and Gross (2009) as a way that is different from traditional student roles, as they go the extra mile rather than just showing school spirit through rallies for example. Correspondingly, Fielding (2004) states that student voice covers a range of activities that encourage reflection, discussion, dialogue and action on matters that primarily concern learners. In addition, Mitra (2007) explains that learners are included in efforts that influence the core activities and structures of their schools. In a school setting, Mitra and Gross (2009) explain three stages involved in learners' voice, which relates to; being heard, collaborating with adults and building capacity for leadership. Figure 1 below shows the pyramid of the three levels of learner voice. 


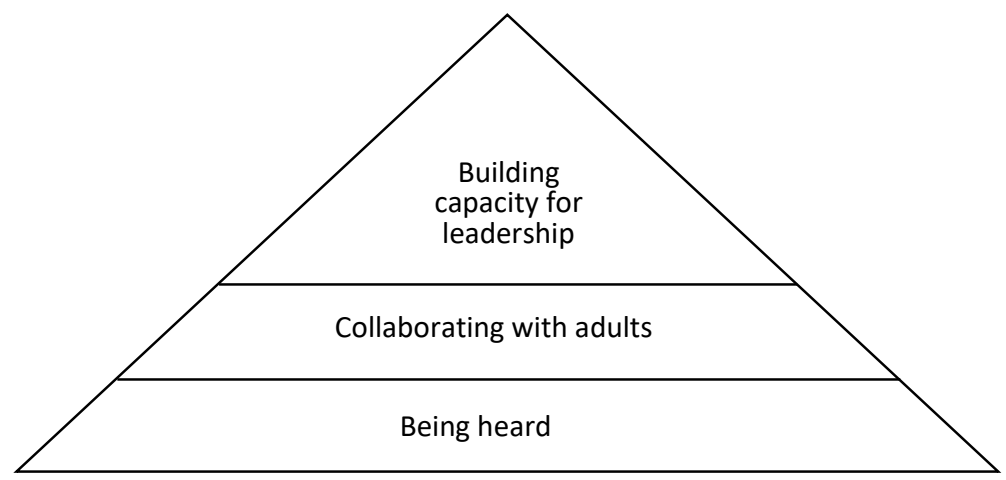

Figure 1: Pyramid of learners' voice

Source: Mitra \& Gross (2009, p. 523)

Figure 1 above illustrates the three key stages through which learners can express their voices. As can be seen in Figure 1, firstly, learners can be heard by encouraging them to express their opinion about issues and advocate for change. Secondly, learners can collaborate with adults to address the problems in schools or seek changes around their schools. Thirdly, learner leadership capabilities can be built through involvement of learners in leadership building activities. The pyramid of learners' voice can be interconnected to distributed leadership which nurtures leadership development in learners (Grant \& Nekondo, 2016). Three stages as illustrated above, provides a good framework for grooming serving and prospective learner leaders. The pyramid provides logical sequence on how learner leadership can be planned, implemented and sustained in schools.

Studies by Mitra (2007) and Hine (2011) have accounted for numerous benefits of giving and hearing learners' voices in schools. Considering student voice has a potential to improve student results and school reconstruction. Similarly, Hine (2011) indicates that there are benefits in giving and hearing students voice as it engenders a sense of pride in their school as they start to feel like they are really part of it. It also provides adults with valuable insights into the dynamics of the school, through the lens of students.

In contrast, Grant (2015) states that learners who have limited opportunities for democratic voice in the educational process, feel their lives, beliefs and hopes are undervalued by schooling and hence develop hostility towards school. Learner voice thus plays a very significant role, as it offers true democracy within the institution and leads to learner participation in developing their schools. Therefore, this paper sought to explore from researcher-interventionist perspectives, opportunities for improving the prospects of learner leadership in schools, guided by the following questions:

a) How is the term learner leadership understood by teachers and learners at the school?

b) What are the roles of the LRC members at the school?

c) What factors enable and constrain learner leadership development in the school?

d) How can LRC voice be invoked through Change Laboratory workshops?

The researcher-interventionist approach was used to address the above questions through the and Change Laboratory Workshops (CLWs), underpinned by the theoretical framework of Cultural Historical Activity Theory (CHAT). CHAT is a situated activity in mediated interactions between subjects, objects, rules, community, the division of labour and tools (Bolden, 2011). In addition, CHAT is concerned with unfolding a practical activity, as well as in intervening in the practice "in order to promote change" (Grant, 2017, p. 14). Based on this understanding, CHAT is a chosen theoretical framing for this interventionist study. The theoretical underpinnings of CHAT are discussed in the following section.

\section{CHAT AS A THEORETICAL FRAMEWORK}

CHAT originated from the work of Vygotsky in Russia around the 1920s and early 1930s. Vygotsky's work on human development and learning was further developed by his colleague Leontiev and, more recently, by Engeström (Yamagata-Lynch, 2010). CHAT has evolved through three generations. The first generation of CHAT emerged from Vygotsky and it centres on the concept of mediation (Sannino, Daniels, \& Gutierrez, 2009). Vygotsky proposed that the relationship between human agents and their environment is mediated by tools. The idea of mediation is represented by a triangular model which entails subject, object, and mediating tools. Mediation opens a way for development and it is acted upon by cultural and historical factors in the course of ongoing human activity (Daniels, 2008). However, there was a limitation to this model, the unit of analysis remains individually focused and thus cultural evolutions were not taken into account (ibid.). This limitation was overcome by the second generation of CHAT which was improved by Leontiev.

The second generation of CHAT was the key framework for this study since the study focused on one collective activity system only. An activity system is described by Mukute (2010) as a group of any size, pursuing a certain goal in a focused way; it is 


\section{Change Laboratory Workshops as Tools for Improving Learner Leadership in Schools: A Researcher-Interventionist Approach}

something collective that brings in the collaborative relations between people and the object (Ploettner \& Tresseras, 2016). Leontiev's second generation shifted the focus from being individually focused to a collective activity with an inclusion of rules, community, and division of labour and how all the elements could contribute to the mediation process (Olavarria, 2013). This generation attempted to clarify the activity itself from actions.

The activity is recognised by its object or goal and therefore, there is a clear distinction between the concepts of actions and activity in this model (Foot, 2001). In addition, an activity is a collective, systematic formation that has a complex mediational structure which produces actions, and is realised by actions. However, activity is not reducible to actions (Daniels, 2008). Actions are individually focused and have a temporary clear-cut beginning and end, which subjects of the activity systems take, in the process of participating in an activity. An activity system, on the other hand, evolves over a length of time, often taking the form of an institution (Daniels, 2008).

The strength of the second generation of CHAT lies in its capability to bring forth interrelations between the individual subject and his/her community. However, this is also the area where internal contradictions caused by tensions can hinder the subject participation in the activity, in trying to reach the object. Contradictions are cultural-historical "evolving tensions that can be detected and dealt with in real activity systems" (Engeström \& Sannino, 2010, p. 4). Contradictions are explained later in more detail under the principles of CHAT. The limitation of the second generation is that it is not accommodative of cultural diversity and perspectives outside the central activity system (Engeström, 2001). Although there is a third generation, it is not within the scope of this study and, therefore, will not be discussed.

\subsection{Elements of the activity system of this study}

There are six elements in the activity system: subjects, rules, community, the division of labour, mediation tools and the object and it is represented as a triangle (Sannino, 2011, p. 574). The triangular pyramid of the activity system for this study is presented below:

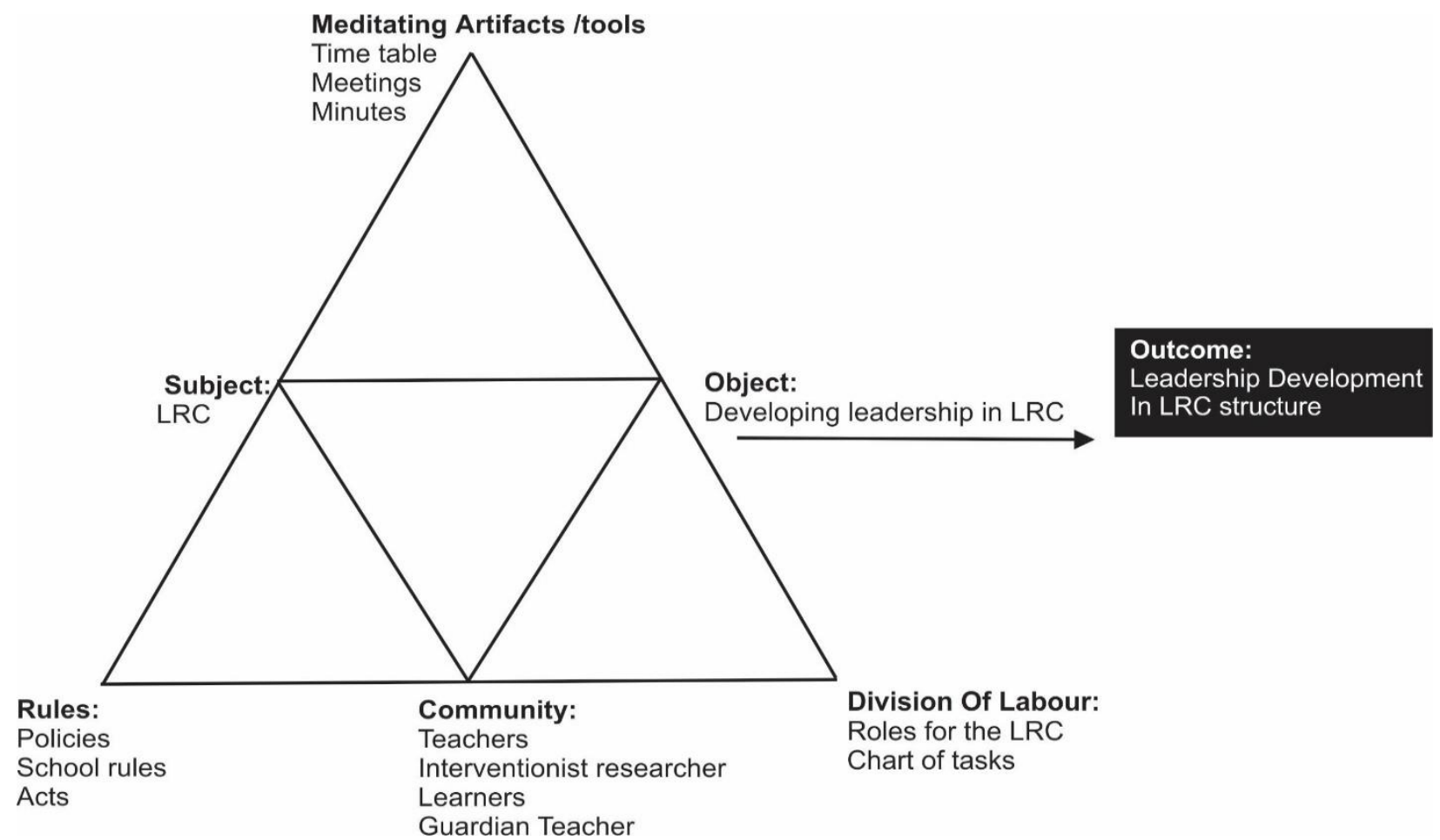

Figure 2: Second generation activity system

Source: Engeström, (1987)

The activity system above shows different elements of the system; in our study, the object of the activity system was the goal that was worked on, which was learner leadership development amongst the LRC. Subjects were the LRC participants. Rules were policies and Acts which mediated the interactions between the subject and the community as well as between the subject and the object. Mediation tools were the minutes, meetings, charts and other tools that were used for understanding and transformation of the object. Community represented the group with interest in leadership development which were the teachers, the researcherinterventionist and other learners. Division of labour was the vertical and horizontal allocation of responsibilities that mediated relations between the community and the object. The interaction between the elements of the activity system develops human 


\section{Change Laboratory Workshops as Tools for Improving Learner Leadership in Schools: A Researcher-Interventionist Approach}

consciousness, and results in a meaning making process that has a potential to transform the subject as well as the object (YamagataLynch, 2010).

\subsection{Five principles of CHAT}

Engeström's model of CHAT is characterised by five principles. The first principle explains the activity system as a unit of analysis (Engeström, 2001). People are interconnected with different activities every day, therefore the activity which people are involved in, is considered the unit of analysis (Ploettner \& Tresseras, 2016). The second one is the multivoicedness of the activity. The activity system consists of different people, who all have various ideas and opinions. Therefore, an activity system is always an interconnected web of multiple points of view, traditions, and interests, which bring forth tension and innovation (Engeström, 2001). The third one is historicity of the activity. The activity system takes shape and gets transformed over lengthy periods of time, therefore their problems and potential can only be understood against their own history (ibid.).

The fourth principle explains the central role of contradictions and tensions as sources of change and development (Engeström, 2001). Activity theory uses the term contradictions to show misfits within or between elements of a single activity system (Foot, 2001). As contradictions emerge, new ways of developing the activity arises and evolve within and between the elements of the activity system (Foot, 2014). There are different levels of contradictions, however, and the study will only present the two levels that were applicable - the primary contradiction which occurs within a single element of an activity system (Foot, 2014), as well as the secondary contradiction, which develops between two elements of an activity (Foot, 2014). The figure below attempts to show how contradictions lie in the activity system of the study.

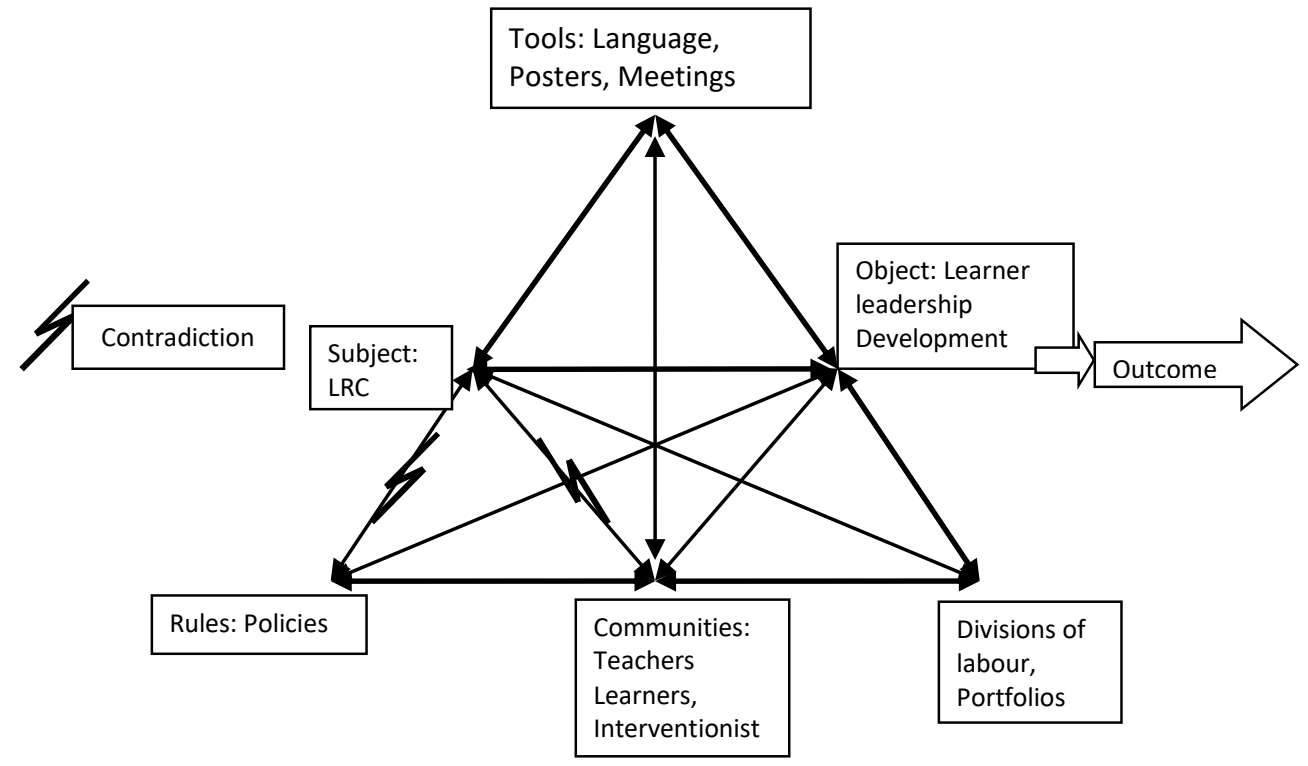

Figure 3: Second generation of CHAT with contradictions

Source: Engeström (2001).

The fifth principle describes expansive learning cycles as a possible form of transformation in the activity (Engeström, 2001). This principle is discussed fully next.

\subsection{Expansive learning}

Expansive learning involves the creation of new knowledge and new practices for a newly emerging activity; it is about learning something which is not yet there as knowledge is being learned as it is being developed (Daniels, 2008, p. 126). In addition, Engeström views expansive learning as a learning process whereby the "subject of learning is transformed from isolated individuals to collectives" (Engeström, 2016, p. 44). The expansive learning process allows growth and transformation of the object by pushing the subjects to exceed and go beyond the problem initially given (Sannino et al., 2009, p. 302). Therefore, expansive learning enables individuals to move towards their Zone of Proximal Development (ZPD), which is the space for expansive transition.

Engeström and Sannino (2010) describe the Zone of Proximal Development as the distance between what an individual can do on their own and what they can do with the help of a more knowledgeable other. An expansive learning cycle has seven stages (Engeström, 2016). However, we only discuss the first three which were covered in this study. Engeström explains the first three of the seven stages of expansive learning cycle as follows: In the first stage, participants are involved in questioning, criticising and rejecting certain existing practices. The second stage involves participants analysing the situation in order to identify causes, by tracing its origin and evolution or by constructing a picture of its inner systemic relations. During the third stage, participants model new solutions (Engeström, 2016). The Figure 4 below summarises the expansive learning cycle. 


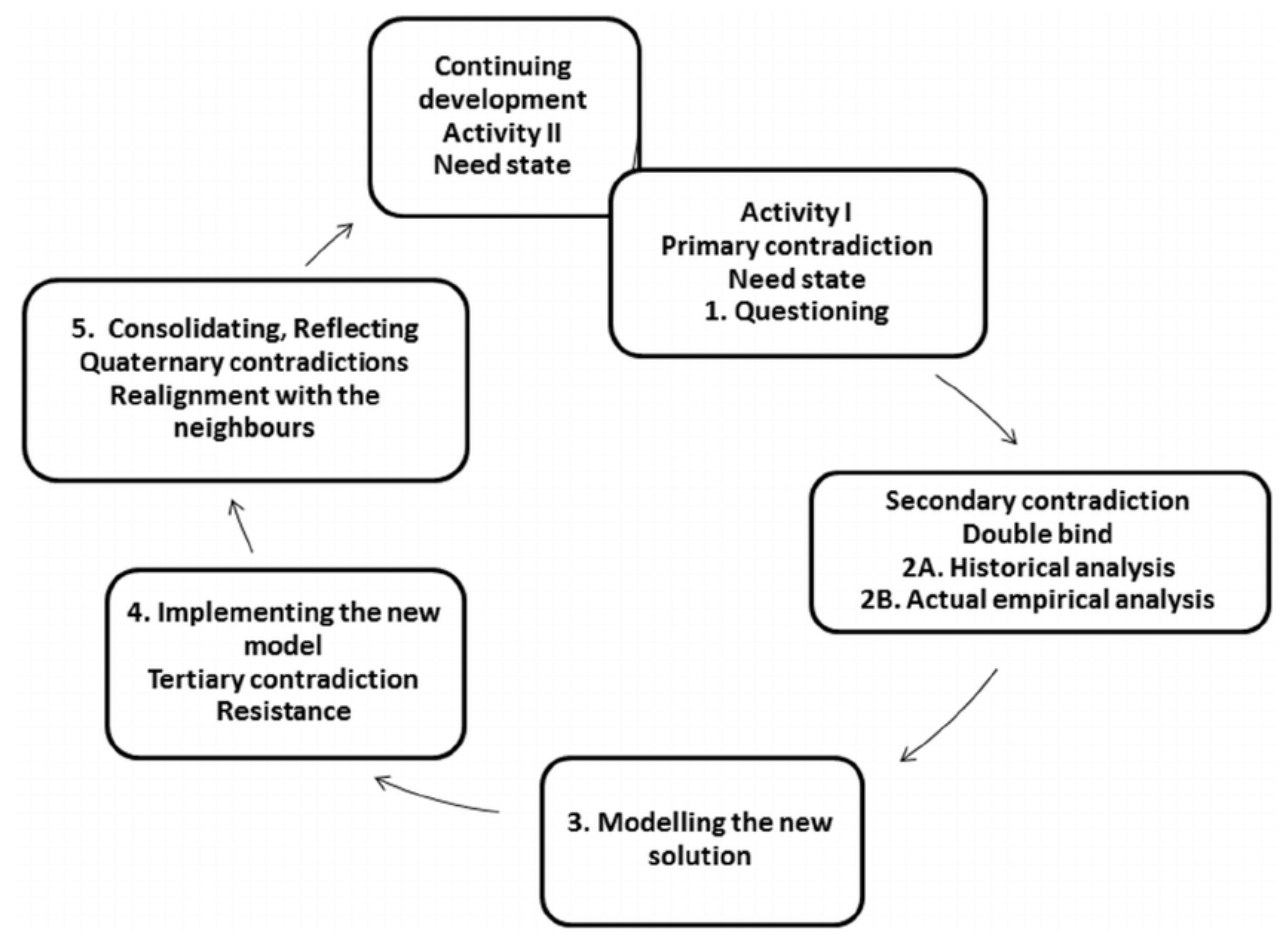

Figure 4: The expansive learning cycle

Source: Engeström (2001)

The LRC members went through three stages of expansive learning which guided the Change Laboratory workshops which are presented below.

\subsection{Change Laboratory intervention}

A Change Laboratory is a novel method and instrument for a developmental intervention to support collaborative learning in and transformation of work activities (Virkkunen \& Newnham, 2013). Change Laboratories are further defined by Virkkunen and Newnham (2013, p. 16) as a "formative intervention method for developing work activities by the practitioners in collaboration with the researcher-interventionist". According to Ploettner and Tresseras (2016), Change Laboratories trigger and support the process of expansive learning where activity systems are transformed and new potential is found.

A Change Laboratory intervention is foundationally built on two principles connected to the theory of expansive learning, the principles of 'double stimulation' and 'ascending from abstract to the concrete' (Ploettner \& Tresseras, 2016). Double stimulation was employed in the study. The mirror data on contradictions provided the first stimulus, while the object and the expanded learning practice helped learners to redesign their activity thus offering the second stimulus. In addition, the principle of ascending from abstract to the concrete was used in the Change Laboratory workshops (CLW) as well. The researcher-interventionist invites participants to think differently - that is to think dialectically about their activity (ibid.). The Change Laboratory intervention thus challenges participants to acquire a different type of thinking about their work (Ploettner \& Tresseras, 2016).

In this study, learners worked with me as a researcher-interventionist in two Change Laboratory sessions to analyse and specify the challenges of developing the activity and creating a new model for it. 


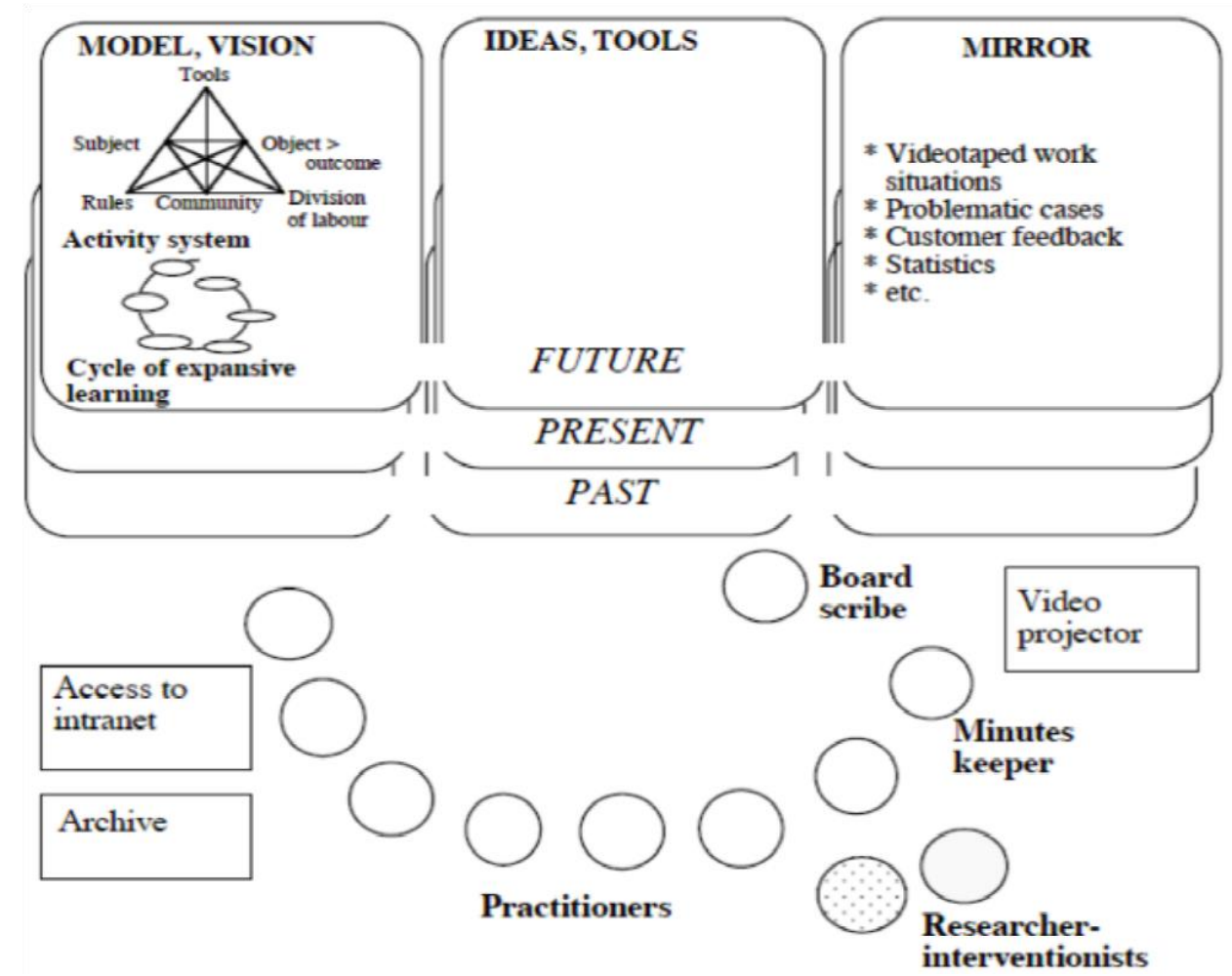

Figure 5: Layout of a Change Laboratory space

Source: Virkkunen \& Newnham (2013, p. 16).

According to Virkkunen \& Newnham (2013), the model/vision surfaces are reserved for modelling the past, present and future structure of the activity and inner contradictions in it (see Figure 2.5). Ideas/tools surfaces are reserved for insights from the participants. Mirror surfaces are used to provide the learners with a mirror reflection of the current practice of learner leadership. The mirror of the present surface is used to represent and examine innovations and experiences from work practices. The mirror of the past, comprises data and observation concerning historical changes in the activity. The mirror of the future is used to represent and discuss follow-ups concerning participant's experiments with new concepts and tools, which they have created and with which they begin to build the future form of the activity (Virkkunen \& Newnham, 2013, p. 16).

\subsection{Relevance of CHAT to our study}

We found CHAT to be of significance to our study because it provided me with an interventionist methodology to engage in. CHAT allowed me to conduct a formative intervention, "a collective effort to understand and face contradictions and the problems that they engender" in the school (Sannino et al., 2016, p. 3). We worked with the LRC as subjects of the activity system, to surface the contradictions, as well as empowering them to own the transformation that emerged from the study. CHAT was thus ideal for studying and transforming practical work activity, allowing learners in the LRC to work on the practical activity of learners' leadership development.

Furthermore, CHAT provided me with a lens to look at learner leadership practice from different perspectives and not to conform to the school environment only. We were able to look at learner leadership development as part of a broader transformation effort, that is inevitable in today's world. We gained an in-depth understanding of the practice and explored the cultural-historical roots and tensions in the activity system. We were able to recognise the fact that learner leadership is not an issue for teachers and learners only, but a societal and national struggle (Ploettner \& Tresseras, 2016).

The usage of CHAT was ideal for our study since it gave learners a platform through Change Laboratory workshops to voice out issues. Learners participated in discussions and decision- making during the Change Laboratory workshops and this resonates with the views of democratic education which is organised around participation in decision-making by all stakeholders, including learners. Therefore, CHAT and Change Laboratory workshops specifically facilitated the development and nurturing of LRC leadership, which might result in eliminating the silence in learner voice which is the focus of the study. We made specific choices for our research study, such as the usage of second generation CHAT and having the LRC members only in the CLWs. We argue that these choices were to do with giving learners the space to speak, since in the African context, had other stakeholders been there, the learners would not have voiced their opinions so openly. 


\section{Change Laboratory Workshops as Tools for Improving Learner Leadership in Schools: A Researcher-Interventionist Approach}

\subsection{The limitations of CHAT}

Firstly, Cultural Historical Activity Theory was developed in Finland, a country with a different socio-economic set up to Namibia. For instance, its principle of multivoicedness might not possibly manifest itself well in an African country such as Namibia, where children are taught to listen and are discouraged from questioning their elders. We perceived this as a threat early in our study, and as a result we decided to conduct Change Laboratory workshops with the LRC members only and excluded teachers, to avoid cultural influence.

Secondly, the Cultural Historical Activity Theory principle of expansive learning is often criticised for not dealing with power issues (Masilela, 2017). It is argued that during the questioning stage, it does not take into account who the participants are. Therefore, it is not clear who is doing the questioning, who is silenced and who is prevented from participating in the questioning (Masilela, 2017). This implies that people who hold positions of power will be more likely to participate, compared to others and this might contradict with the intention of distributed leadership theory.

Thirdly, CHAT is an object-oriented theory. Engeström and Sannino $(2010$, p. 4) indicate that the object is the resistant raw materials, future-oriented purpose of an activity and is the true carrier of the motive of the activity. However, Nussbaumer (2012) argues that if the object is the driving movement for development and change, the model needs to be rethought, as it misses articulation of societal contradictions. Society could also drive the subject and not only the object.

The next section presents the methodology used for the study.

\section{RESEARCH METHODOLOGY}

The methods and techniques used for the study are described according to the following outline:

\subsection{Research design}

A qualitative research approach was used for the study. The empirical investigation made use of a case study design, as an intensive analysis and description of a single phenomenon for an enriched understanding of what is going on with the phenomenon (Simons, 2009; Cohen, Manion, \& Morrison, 2000). The case study design was the ideal research design to use as the researchers intended to get intensive description of the specific challenges that faced learner leadership in schools. Case study designs enabled researchers to acquire a comprehensive understanding of how participants relates to the subject being studied, and how they interact with each other in a specific situation (Maree, 2007; Simons, 2009). The interaction with different teachers and learners brought multiple perspectives of the complexity and uniqueness of the challenges that faced learner leadership in a real-life context.

Since case study help researchers set boundary for their studies (Berg, 2001), the researchers were able to focus on a particular, specific group of learner leaders which was the Learner Representative Council members (LRC). The set boundaries helped researchers concentrating and focusing on the participants, detailing the challenges they faced in their leadership as learner leaders. In addition, the flexibility inherent in case study designs (Maree, 2007), allowed the study to be conducted for numerous days and collected data at different times and places during the research for enriched data and richer data analysis. The flexibility also allowed researchers to use multiple sources of data and different techniques in the data gathering process, which enhanced the validity of the data collected and subsequent results.

Despite the benefits of the case study as relates to flexibility, case study investigations are associated with certain limitations. The findings of case studies cannot be generalised. This limitation did not apply to this study as the researchers had no intentions to quantify the findings and generalise them over large populations, other than the population from which the participants were drawn. The findings were meant for application to the population from which data were collected. Notwithstanding the centrality of the findings around the cases studied, the researchers have provided a thick description as a measure of minimising limitations related to generalisation of findings (Rule \& John, 2011).

In reporting the research process, the researchers have provided adequate and rich information related to the research processes, findings and conclusions to enable other scholars and readers gain a level of reader-determined transferability, if they believe that the research processes and findings resonates well with other cases familiar to them. This implies that readers can infer from the detailed descriptions of the study as provided, whether the findings are applicable to their settings, without necessarily being provided with statistical evidence which are traditionally associated with generalisation.

The next section presents the research site and participants of the study.

\subsection{Sampling and participants}

Seventeen participants took part in the research, comprised of twelve Learner Representative Council members at the school, who were all learners and were considered the primary participants; two other learners who were class monitors and were involved in piloting the questionnaires; the School Principal, a Head of Department (HoD), and the Liaison teacher for the LRC. Purposive sampling was used as a sampling technique for the researchers to select individuals for the sample, depending on the characteristics 


\section{Change Laboratory Workshops as Tools for Improving Learner Leadership in Schools: A Researcher-Interventionist Approach}

that the researchers were looking for (Gay, Mills, \& Airasian, 2009). The criteria that informed sampling included leadership positions, leadership potential, and the ability to provide better insights into the phenomenon of the study.

Purposive sampling made it possible to choose participants that were knowledgeable of the subject being studied, thus capable of providing the data needed for the study (Maree, 2007). LRC members were chosen because they were the focus of the study. The principal and the HoD were better positioned in the school management and were thus knowledgeable of the leadership challenges that faced learner leaders at school. The Liaison teacher was a focal teacher to the LRC members, charged with the function of mentoring, coaching and guiding of LRC members within the school, and thus better positioned to highlight the challenges that faced learner leadership. The purposive nature of the sampling decisions in respect of the research site and participants enabled researchers to obtain the richest possible source of information fit for addressing the intentions of the study.

\subsection{Data generation}

The data for this study was generated in three main phases and the research process was conducted over a period of 8 weeks.

\section{Phase one}

Phase one was completed in a period of five weeks. The goal for phase one was to understand learner leadership development at the school. Therefore, we completed a contextual profile for the school. This allowed me to dig deeper and gain insights into the past and present on learner leadership. The data was collected through interviews, questionnaires, observation, and document analysis, and the data was aimed at enhancing our understanding of how respondents viewed the phenomenon. This phase answered the following research questions: How is the term learner leadership understood by teachers and learners at the school? What are the roles of the LRC members at the school? What factors enable and constrain learner leadership development in the school?

\section{Phase two}

Phase two was conducted over a period of one week. The goal for this stage was to conduct an intervention in order to bring about change. There were two Change Laboratory workshops (CLW) conducted in the Computer Laboratory of the school. We only had LRC members in the Change Laboratory session because we wanted learners to speak freely and invoke their voices without being obstructed by the teachers' presence.

This phase sought to answer our final research question: How can LRC voice be invoked through Change Laboratory workshops? In the first CLW, we mirrored the data from phase one using visuals. In the second CLW, we discussed the contradictions that emerged and attempted to find generative solutions to them. The doable solutions were recommended for implementation. This second phase of the data collection focused on the activities of the Change Laboratory workshops which We observed and made notes on. We entered a process of reflective journaling; drawing out themes and making comments on the processes of the workshops from the notes. This journal provided a final data source.

A Change Laboratory is underpinned by an expansive learning cycle. During the Change Laboratory sessions, learners were involved in transformation of leadership practices; contradictions around the object of transformation were presented and it is during these deliberations that expansive learning occurred (Sannino, Engeström, \& Lemos, 2016). Expansive learning has seven stages of the learning cycle (Engeström, 2016). However, in this study, the learners were only able to reach stage three of the cycle. The diagram below shows the main types of expansive learning actions that the LRC members were involved in.

Table 1: The expansive learning table

\begin{tabular}{|l|l|}
\hline Action 1: Actions of questioning & $\begin{array}{l}\text { The LRC members were involved in questioning the } \\
\text { LRC leadership practices. }\end{array}$ \\
\hline Action 2: Actions of analysing the situation & $\begin{array}{l}\text { The LRC members analysed the past, discussing what } \\
\text { the former LRC used to do and how the contradictions } \\
\text { that emerged were solved in the past. }\end{array}$ \\
\hline $\begin{array}{l}\text { Action 3: Actions of modelling new explanatory } \\
\text { solutions }\end{array}$ & $\begin{array}{l}\text { The LRC members were involved in modelling; they } \\
\text { discussed and searched for solutions to the } \\
\text { contradictions that emerged in the study. }\end{array}$ \\
\hline
\end{tabular}

Source: Virkkunnen \& Newnham (2013, p. 46)

Table 1 above outlines the main actions that learner leaders were involved in, and the specific activities that were involved in.

\section{Phase three}

Phase three was completed in two weeks. The goal of this phase was to surface any information that may have been collected but not clearly voiced. We gave the interview transcriptions to the three interviewees and asked them to verify what appeared in the hard copies. The idea behind member-checking was to verify our understanding of what We had written with the participants (Maree, 2007). The analysis of the data started at this stage and we also ensured that we had collected sufficient rich data. 


\section{Change Laboratory Workshops as Tools for Improving Learner Leadership in Schools: A Researcher-Interventionist Approach}

\subsection{Data collection tools}

In this section, we present the data collection methods and techniques used, as well as the reasons for our choices. The benefits and limitations for each method are addressed. The data for the study was collected using document analysis, semi-structured questionnaires, interviews, observation schedules, and journaling. The range of data collection tools was valuable for this study, because it allowed for the constraints of one to be supplemented by another which, in turn, provided me with rich and meaningful data. With the permission of participants, we used an audio recorder and camera for data capturing.

\section{Document analysis}

Document analysis was also used as a data gathering tool. Document analysis is a "systematic procedure for reviewing or evaluating printed or electronic material" (Bowen, 2009, p. 27). Specific documents were analysed in order to gather evident information on leadership opportunities that existed at the school. The document analysis further provided me with a picture of the school, before administering other data collection tools. The term 'documents' refers to a "wide range of written, physical, and visual materials, including what other authors may term as artefacts (Jacobs \& Walker, 2014, p. 471). The documents examined in the study were: Minutes of LRC meetings; School Code of Conduct/School Rules; and documented presence of the LRC members in the School Development Plan and in the Plan of Action for Academic Improvement. These documents were chosen specifically because they were used as guides and were likely to reflect what happens at the school in terms of learner leadership development. We gathered documents from files, computers, and notice boards; hence this has proved to be good original source of information for the study. Document analysis was used during phase one to answer the first three research questions.

There are numerous benefits of using document analysis as a source of data. Document analysis provided the study with a stable source of data and descriptive information (Jacobs \& Walker, 2014, p. 471). The documents are a significant corroboration of the evidence from other sources (Maree, 2007, p. 83). This made it substantive for the study, as it allowed the usage of other data collection tools in the seeking of answers to the research questions.

We should however acknowledge that document analysis has limitations, such as how some data was "recorded for a different purpose than the current research purpose" (Johnson \& Christensen, 2012, p. 212.). This might mean that the information provided by the documents might not be sufficient; however, in this study, the document analysis was not used in isolation. Therefore, whatever information that might have been lacking in the documents, was obtained in other data collection tools.

\section{Semi-structured questionnaires}

At the first level of the research process, we aimed to gather understanding of learner leadership development phenomena, as well as factors that influence leadership in the school. We therefore administered semi-structured questionnaires to the learners to ascertain their understanding. According to Bertram and Christiansen (2014), a semi-structured questionnaire has open-ended questions that participants may answer as they like, in the space reserved. The purpose of the semi-structured questionnaire is that it "enables the researcher to standardise the questions asked and to control the amount of information that respondents supply" (Bertram \& Christiansen, 2014, p. 79). All 12 LRC members were given the questionnaires and they provided a "written collection of self-report" based on the questions (Gay et al., p. 373, 2009) during phase one of data generation. The questionnaire aimed to answer both research question one and three.

In terms of the process, learners were briefed about the administration and completion of the questionnaires. Written consent was obtained from their guardians. We must admit that the completion of the questionnaires was not done in our presence, as learners were given the questionnaires during their tea break and were requested to hand them back after their study sessions in the afternoon. This might have posed as a limitation as we may never know whether the LRC participants actually completed the questionnaires or someone else completed it for them (Maree, 2007). However, filling the questionnaires without pressure from the researcher, provided learners with an opportunity to reflect on their writings and to provide me with rich data. In addition, the completion of the questionnaire without our presence further minimised our influence on the learners, making the tool suitable for the study (Maree, 2007).

The questionnaires were beneficial since they enabled triangulation; some of the questions that were in the questionnaires, were also in other data collection tools and this provided me with comprehensive data. Furthermore, questionnaires offer anonymity which is promised in the study, bearing in mind that learners are minors.

\section{Interviews}

The study used interviews as a source of data, which were conducted with three teacher participants during break-times. Thomas $(2009$, p. 160) defines interviews as "a discussion with someone in which you try to get information". It is more than a conversation with a purpose. In addition, interviews "enable participants to discuss their interpretation of the world in which they live, and to express how they regard situations from their own point of view" (Cohen, Manion, \& Morrison, 2011, p. 409). Therefore, interviewing the teachers assisted me in gathering an understanding of learner leadership, as well as the information on leadership opportunities in the school. The interviews occurred during phase one of data generation and they answered research question one and two. 


\section{Change Laboratory Workshops as Tools for Improving Learner Leadership in Schools: A Researcher-Interventionist Approach}

The first benefit of the interview for the study was just as the questionnaire; it was used with other methods in the gathering of data and gave me a chance to triangulate (Drever, 1997). Furthermore, we used a semi-structured approach in the interviews, which provided me with an opportunity to ask the prepared questions according to the interview schedule, but gave me the benefit of probing for clarifications (Thomas, 2009). The interview allowed me to probe for detailed information on the past, present, and future leadership opportunities for learners at the case study school. This made interview an appropriate method of data collection for the study.

Interviews have their limitations since it is a social and interpersonal encounter, therefore, power relations and biases might occur. To minimise the influence, we practiced self-disclosure at the beginning of the interview, which is sharing personal information about ourselves, in order to connect with the participants (Lichtman, 2014). This helped in creating rapport with the teachers.

\section{Observation}

Observation is defined as "the process of gathering open-ended, firsthand information by observing people and places at a research site" (John, 2014, p. 235). During the observation we examined "behavioural patterns of people in certain situations to obtain information about the phenomenon of interest" (Johnson \& Christensen, 2012, p. 206). We observed an LRC meeting, a staff briefing, the morning devotion, the rotational process, and Change Laboratory sessions. During these observations, We noted down striking features about power relations in terms of gender, grade, language, and portfolios. We also tried to observe in terms of CHAT, examining the interactions of one element of the activity system (the LRC) during the workshops. The observation schedule guided our observations in response to research question four.

Observation is a method of generating data which entails the researcher getting fully involved in a research setting, in order to experience and observe first-hand a range of dimensions in and of that setting (Mason, 2002). We were therefore a participant observer, which is referred to as "when a researcher participates in the situation, while observing and collecting data on the activities" (Gay et al., 2009, p. 366). Being a participant observer helped me to gain insight and develop relationships with the participants which may not have been attained by a researcher who was not a participant in the study (ibid.).

Observation was greatly beneficial for the study because it provided an "opportunity to record information as it occurs in a setting, to study actual behaviour and to study individuals who have difficulty verbalising their ideas" (John, 2014, p. 235). We were able to record the information on learner leadership development from participants based on the live data (Cohen, Manion, \& Morrison, 2000). The observation was an ideal data collection method since it assisted me to verify what is said in comparison with what was actually happening on the school grounds, and further afforded me an opportunity to triangulate with data collected using other data collection tools.

Observation has limitations, such as that the observer may import pre-formed judgements that are not backed by evidence of direct observation (Simons, 2009, p. 62). This happens because observation is selective and thus what is recorded is usually based on the researcher's view of the world. We acknowledge observation may be biased as "it is almost impossible to eliminate subjectivity in qualitative research thus it is best to recognise it and move with it" (Lichtman, 2014, p. 36). However, we have done our utmost to reflect only on what we observed.

\section{Journaling}

The last tool used was journaling. Its primary focus in this study was for the researcher to be self-reflective (Janesick, 1999). This tool allowed me to reflect on the research process as it progressed. We were able to note down the positives, the negatives, what the process meant to me at those specific times, and what we learned from the experience.

The advantage of the journal is that it offers "interesting and vivid experiences that may be subjective, however, bringing them up front allows future researchers to find ways around problems in their own research" (Berg, 2001, p. 276). We noted down our journey during CL workshops, as well as throughout the research process to intensify professional awareness, as well as to allow for informed professional decision-making (Borg, 2001). The journaling was able to contribute to the study in its own way.

Having provided a clear understanding of the process of data collection, we next move on to the discussion of how the data was analysed.

\subsection{Data Analysis}

Data analysis is the process of making sense of the data collected (Merriam, 1998). Data analysis involves the researchers conducting a data reduction process by selecting, simplifying and transforming the raw data as gathered in the field (Bertram \& Christiansen, 2014). The data collected was analysed inductively, by establishing themes. During the inductive thematic analysis, the raw data was examined, labeled and coded according to the responses of the respective research questions (Rule \& John, 2011). The data set were coded on sticky notes which were later pasted into a visual form for an enriched understanding of emergent findings.

The coded portions of data were then grouped logically into categories, which were constructed based on patterns and similarities emerging from data (Merriam, 1998). Thereafter, themes were created as research findings. After creating themes, the researchers scanned through the data again several times to look for other pertinent information that could enhanced the interpretation, and in 


\section{Change Laboratory Workshops as Tools for Improving Learner Leadership in Schools: A Researcher-Interventionist Approach}

the process, more categories were formed for a richer interpretation and discussion processes (Lichtman, 2014). The themes were interpreted and discussed, drawing useful insights from the theoretical frameworks and citing empirical evidence as reviewed, and borrowing participants verbatim. Relating the discussion to the theories helped to validate the theoretical frameworks as adopted as well as confirming the correctness of the literature reviewed as it correlated with current research establishments.

The trustworthiness of the results was established through the measures described in the following section.

\subsection{Trustworthiness of findings}

To ensure the credibility of the results, the study collected sufficient data using multiple data collection technique and the resultant discussions provided were rigorous enough to provide convincing justifications. Two class monitors were given questionnaires prior to the main study as piloting. The piloting was done with the intention "to check for clarity and to remove ambiguities" in the data collection technique (Cohen et al., 2011, p. 402). Elimination of ambiguities in the data collection techniques means that the questions were clearly understood by the respondents and correct answers were thus provided. Interviews were recorded and the participants were given an opportunity to change any wording that they felt did not capture the exactness of their words and intentions.

A very good rapport was built with the participants before the commencement of the interviews, which ensured that participants were open to express their ideas freely to the researchers. The use of data triangulation, which is the use of multiple methods to collect data, strengthened the validity of the qualitative data (Gay et al., 2009). The data sets were corroborated by relating findings from one data collection technique to the data collected with another technique (van der Mescht, 2002). Collaboration ensures congruence of the data, eventually producing results that draws on the strengths of individual data collection technique.

In addition, one of the researchers works for the Ministry of Education, Arts and Culture, which exposed the researcher to insider positionality in this study, as the researcher has also previously worked at the school. According to Chavez (2008, p. 475), insider positionality is about "sharing multiple identities such as race, ethnicity, and class with participants". The advantage of insider positionality was that the researcher had commonalities with the participants which helped obtaining efficacious data from the participants. The influence of the researcher was minimised by building rapport with the teacher participants before the interview, and by code switching to using Oshiwambo, the language that the participants were most comfortable with.

\subsection{Ethical considerations}

All the participants were treated with respect and dignity. The researchers explained all the details related to the study to the participants so that participants were well informed with the intentions of the study, to enable them to make an informed and conscious decision whether to participate in the study or not. Permission to research was obtained. A "permission to conduct research in a school does not substitute the informed consent of parents" (Wassenaar, 2007, p. 73). Hence, informed consents were obtained from the parents and teachers as well as assenting from learners. Participants were informed that the reporting of the researcher processes will be presented in a manner that makes it difficult to be identified or related to the data they provided. The human images that were taken during contact sessions were coloured on the faces to make it difficult for anyone to identify the participants.

As the participants indicated that they wished to have their true identities concealed, pseudonyms were used for the both the school and the participants in the reporting of the findings. The interview with the mentor teacher is captured as IMT, interview with the school principal is captured as IPR, and the interview with the Head of Department is captured as IHOD. The questionnaires that were administered to respective LRC members are captured as LQ1-12, and DA1-7 was used as code for document analysis. Findings collected with other different techniques were also coded differently, such as JE1-7 for journal entries and OBN1-2 for observation notes. Participants were informed of the confidentiality of the data and were assured that the data would not be made public, and will be stored in a locked desk drawer and backed up as soft (digital) copies and saved on the cloud.

The next section presents the discussions of the findings that were established.

\section{DISCUSSION OF FINDINGS}

The Change Laboratory Workshops (CLWs) is a formative intervention method that was used to mirror the contradictions that emerged in learner leadership development efforts for the activity system. The findings indicated that the CLWs were partially successful. The partial success was attributed to the fact that learners in the Representative Council sought solutions and planned on how to address contradictions and challenges. In addition, a plan of activities of what the LRC members would be doing for the rest of the year, was drawn up. As researcher-interventionists, the role of the researchers were to intervene by asking provoking questions and supporting the process, while ensuring that the LRC members led and owned the process (Sannino et al., 2016).

The following sections on the findings of the Change Laboratory Workshop are organised as follows: The Change Laboratory workshops, solutions to the contradictions that surfaced in the study, solutions to some challenges that emerged in the study and the outcome of the Change Laboratory workshops. 


\section{Change Laboratory Workshops as Tools for Improving Learner Leadership in Schools: A Researcher-Interventionist Approach}

\subsection{The Change Laboratory workshops}

The first Change Laboratory workshop focused on mirroring the data. This was attended by all 12 LRC members and a mentor teacher whose duty was to take pictures and video only. We introduced Engeström's second generation triangle to the LRC members and discussed how contradictions can exist within and between the elements of the system (Engeström, 2001). The mirror data which comprised contradictions and challenges, was used as a stimulus for workshop discussions while the object of the activity system offered the second stimulus (Ploettner \& Tresseras, 2016). Therefore, double stimulation was employed in the research study. Engeström's model is characterised by a principle of multivoicedness, whereby the LRC members were involved in debate, negotiation and orchestration (Engeström \& Sannino, 2010, p. 5). During the discussions, the LRC members felt that some of the challenges and contradictions were similar, so they started combining what they understood to be similar or related. By the end of the first workshop, the LRC members had discussed all the constraints and had placed the contradictions on the CHAT triangle. The picture below was taken during the first Change Laboratory workshop.

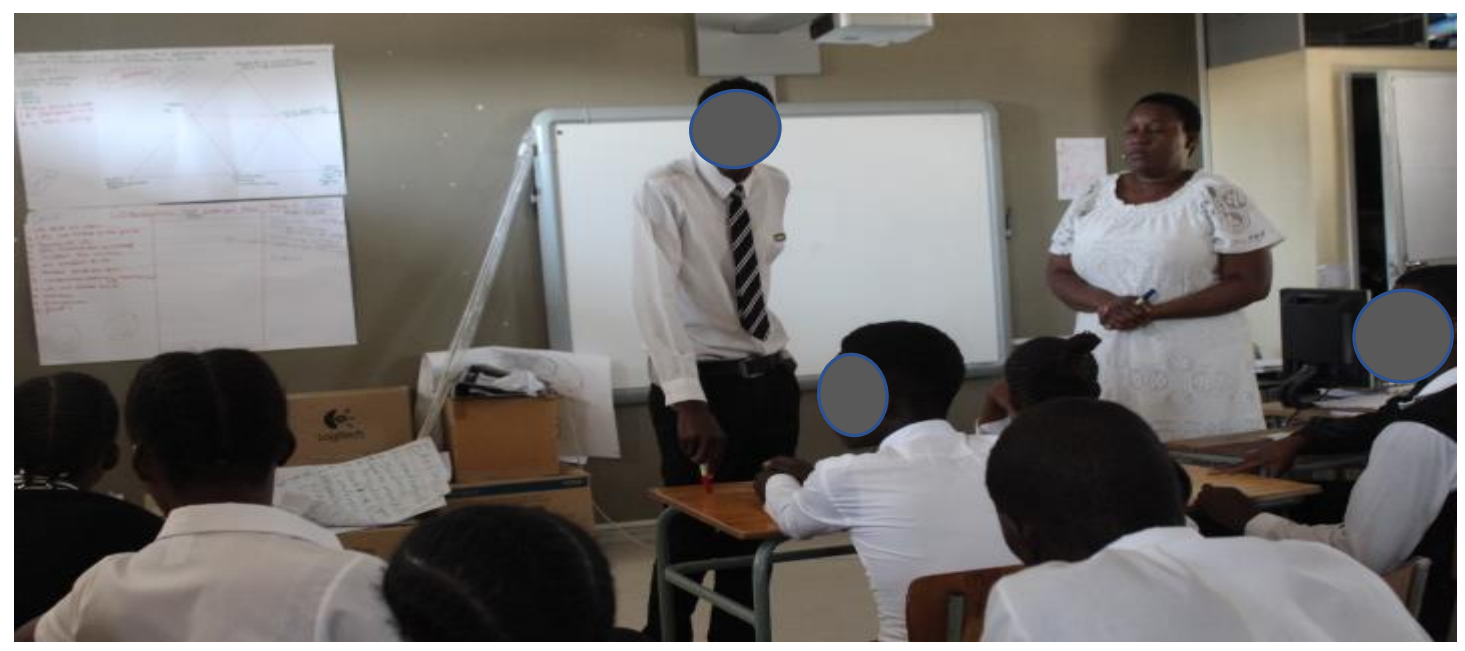

Figure 6: The LRC members during the first CLW

On reflection of the first day of the CLW, we noted a need to encourage the LRC members to use their mother tongue. We hoped that it would encourage more learners to participate in the second workshop. Literature advocates that language is a means of transmitting culture and cultural identity (Namibia. MBESC, 2003). The usage of the mother tongue might help in retaining cultural values embedded in it and traditional ways of expression which might be obscured by the use of another language (ibid.). Similar views were expressed by other studies. For example, one of the well-known Zimbabwean authors and Shona-speaker, Dambudzo Marechera was quoted describing the effect his second language, had on him (Tötemeyer, 2010, p. 27). He said that "I lost the ability to express the simplest things ... I incessantly talked disjointed nonsense ... I felt raped inside through the conflict between Shona and English ... I felt literally as if my words had been stolen". This basically implies that some people find themselves passive, helpless and confused when expected to express themselves in a second language. The picture below depicts an LRC member facilitating the first Change Laboratory workshop.

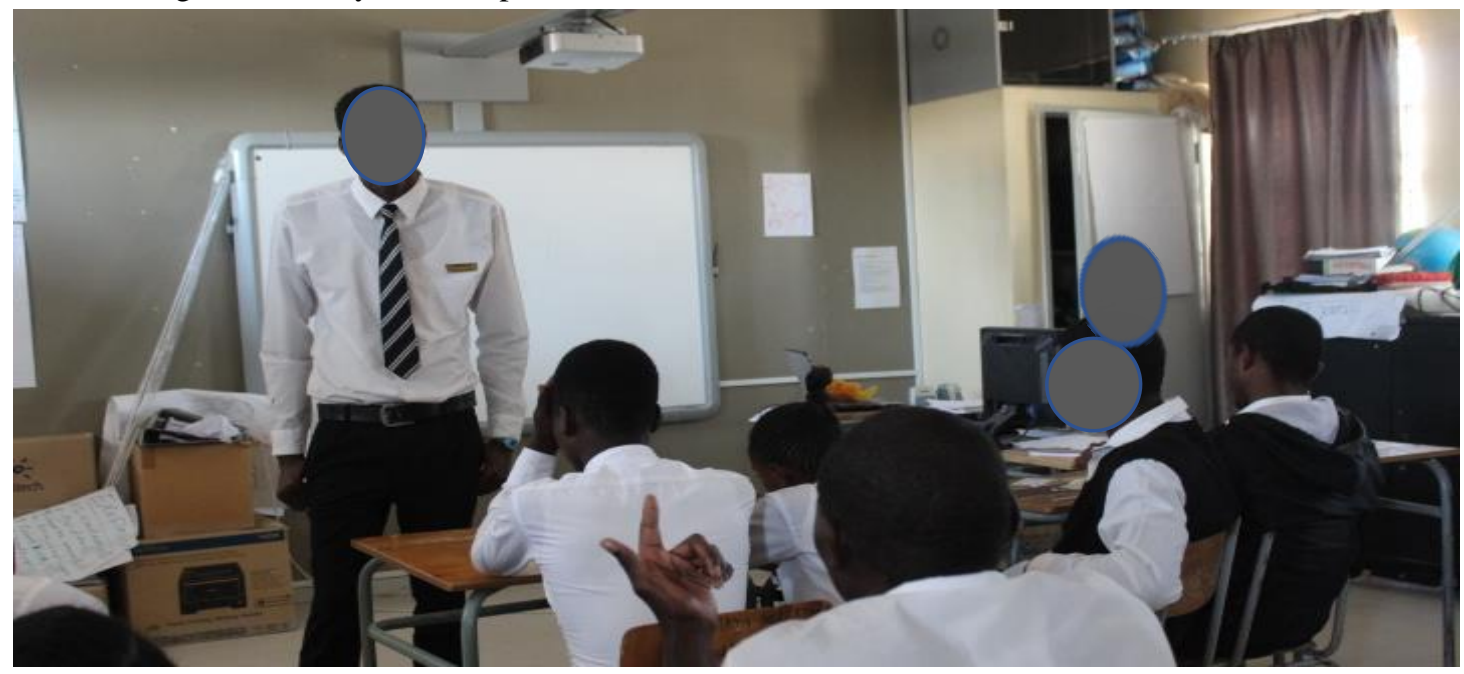

Figure 7: An LRC member facilitating the first CLW 


\section{Change Laboratory Workshops as Tools for Improving Learner Leadership in Schools: A Researcher-Interventionist Approach}

In addition, we also recognised a need to encourage female learners to take part in facilitating the workshop. The idea was to ascertain whether there would be a change in the interactions. The notion was to redistribute power in terms of gender.

The second Change Laboratory workshop focused on finding solutions to the contradictions and to the challenges that emerged (Virkkunen \& Newnham, 2013). It was conducted with nine learners only and no teacher was present. The discussion started with how the contradictions listed in the posters were resolved in the past. Most of the learners seemed not to have ideas of the past solutions. One of the learners presented on what she could remember concerning historical changes in learner leadership development with reference to the contradictions. Thereafter, the focus changed to the mirroring of the future which is used to present solutions (ibid.). Sannino (2009) asserts that mirrors are used as stimulus for stimulating and provoking discussions during Change Laboratory workshops.

\section{Solutions generated in the CLW}

The LRC members deliberated and sought a model solution for the lack of support from the side of the teachers. The learners in the Representative Council recommended that the principal "delegate teachers on a rotational basis to guide and facilitate any initiative that the LRC might come up with" (OBN2, p. 23). The LRC members further emphasised a need for the "principal to organise short training on leadership for all the teachers in the school" (JE7, p. 27). Udjombala (2006) highlights that training equips individuals with the skills and knowledge needed to address the needs of the organisation. Thus, training might develop teachers' understanding of contemporary leadership practices.

\section{The model solutions to disciplinary issues}

The LRC members emphasised that the "teachers should make a follow-up on offences reported by the LRC and punitive measures needed to be implemented to the offenders" (OBN2, p. 23). They further explained that the discipline in the school would only "change if the LRC were given the power" (OBN2, p. 23) to help the teachers maintain discipline within the school surrounds.

\section{The model solution to silence of learner voice}

The LRC members argued that the "two learners assigned to the School Board be invited to future School Board meetings" (JE7, p. 27). In addition, the LRC members emphasised that "they want to be free and able to give their ideas or suggestions straight to the principal and not follow the established channel of communication" (OBN2, p. 23).

\section{Solutions to factors constraining learner leadership development}

Apart from modelling the solution, the learners sought ways to overcome the challenges hindering learner leadership development. On policy limitations, the LRC members did not deliberate on policy as such, but on the LRC schedule at the school. It was resolved that there was a need to have a "schedule to guide the activities of the year. The schedule would make planning easier. The LRC agreed to draw up a draft of activities for the rest of the year at the end of the Change Laboratory workshops" (OBN2, p. 23).

The solution to the challenge of lack of confidence could not be resolved straight away by the LRC members. The discussion moved to the causes of low confidence levels. Further discussions led to the revelation that "their roles were not really clear to them which also had an impact on their confidence" (JE, p. 27). For instance, they commented that "other learners approached them on certain issues and because they were not clear on their roles, they ended up not able to help and that made other learners look down on the LRC members" (JE, p. 27). The learners in the Representative Council emphasised the need to have "their roles explicitly explained to them" (OBN1, p. 23). They also recommended that the "LRC be introduced to other learners at the assembly whereby other learners would also be informed of the LRC duties" (JE, p. 27).

Throughout the Change Laboratory workshops, the learners in the Representative Council were involved in solving contradictions which are starting points for expansive learning (Foot, 2001). During the expansive learning process, the participants search for solutions to contradictions and moved towards their zone of proximal development which is the space of expansive transition (Sannino et al., 2009, p. 302). The Change Laboratory workshops allowed the LRC members to be involved in three different stages of the expansive learning cycle (See Figure 8). The first stage is when learners were involved in questioning and critiquing the practice of learner leadership development in the school. During the second stage, they tried to trace the history of learner leadership development. In the third stage, the LRC members engaged in modelling new solutions (Engeström, 2016). 


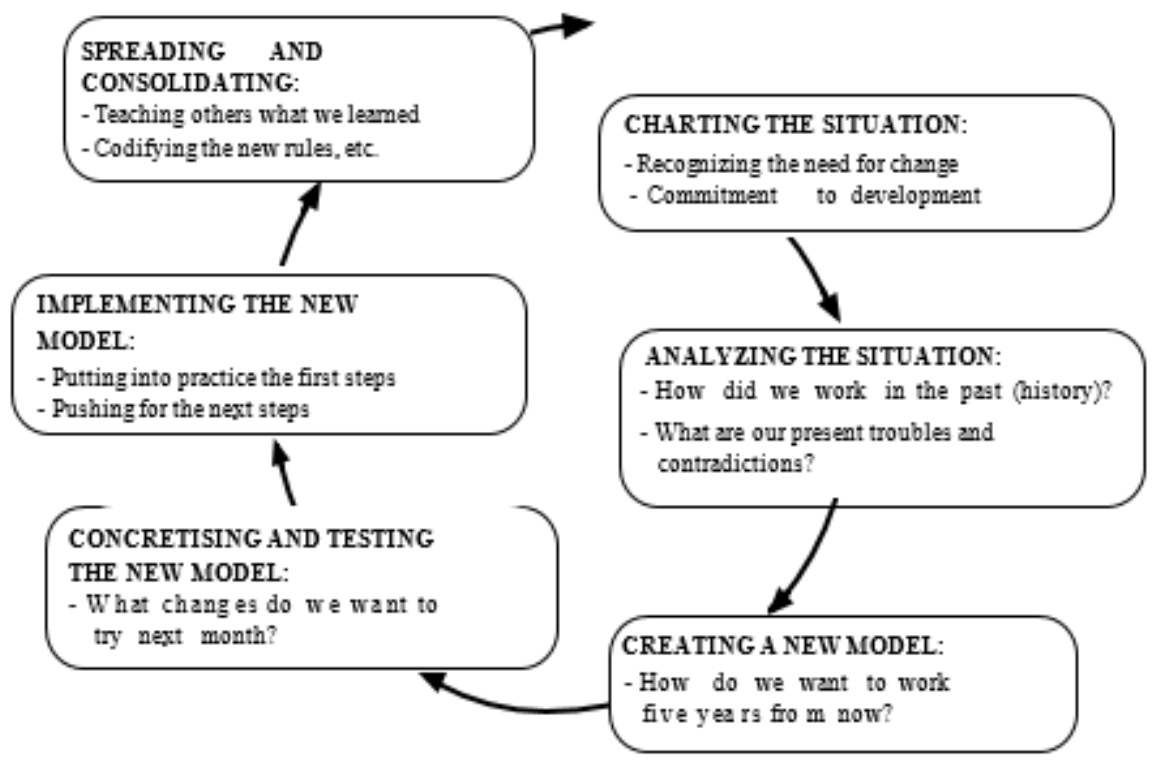

Figure 8: The phases of Change Laboratory process

Source: Virkkunnen \& Newnham, (2013, p. 46)

In addition, the Change Laboratory workshop facilitated the principle of ascending from abstract to the concrete which is connected to expansive learning (Ploettner \& Tresseras, 2016). As a researcher-interventionists, we invited participants to think differently, that is to think dialectically about their activity, therefore, triggering participants to acquire a different type of thinking about their leadership practice (Ploettner \& Tresseras, 2016).

Upon careful reflection of the second CLW, it was evident that a female learner did not stick to her mother tongue during the presentation. She instead code switched between Oshiwambo (which is her mother tongue) and English (which is the medium of instruction at the school). This seemed to arouse the interest of all the learners during the CLW. They would code switch as they questioned and probed further during the facilitation process. Literature suggests that code switching allows learners to discuss ideas that they might not express in English and disclose ideas which would have been concealed if they were to observe exclusive English use in the workshop (Kamati, 2011). In addition, the LRC members seemed to find it easier to interact with the female facilitator rather than the head boy and deputy head boy. This implies that power sharing and code switching might invoke learner voice during the Change Laboratory workshops.

\subsection{The outcome of the Change Laboratory Workshops}

The Change Laboratory success is attributed to the drawing up of the LRC plan of activities for the rest of the year. This implies that by the time we left the school, the LRC members had an idea of what activities they would be conducting and when.

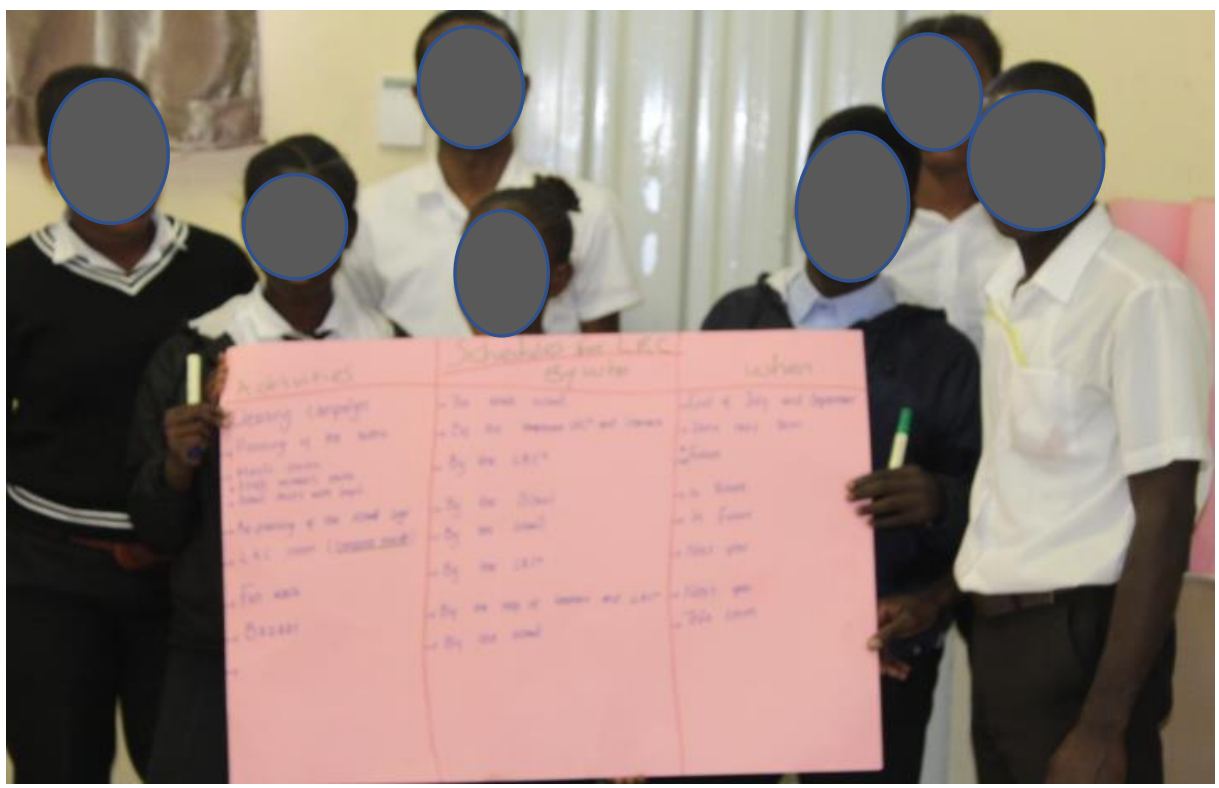

Figure 9: The LRC members holding a poster with planned activities for the rest of the year 


\section{Change Laboratory Workshops as Tools for Improving Learner Leadership in Schools: A Researcher-Interventionist Approach}

The enlarged picture of the planned activities is shown by Figure 10 below.

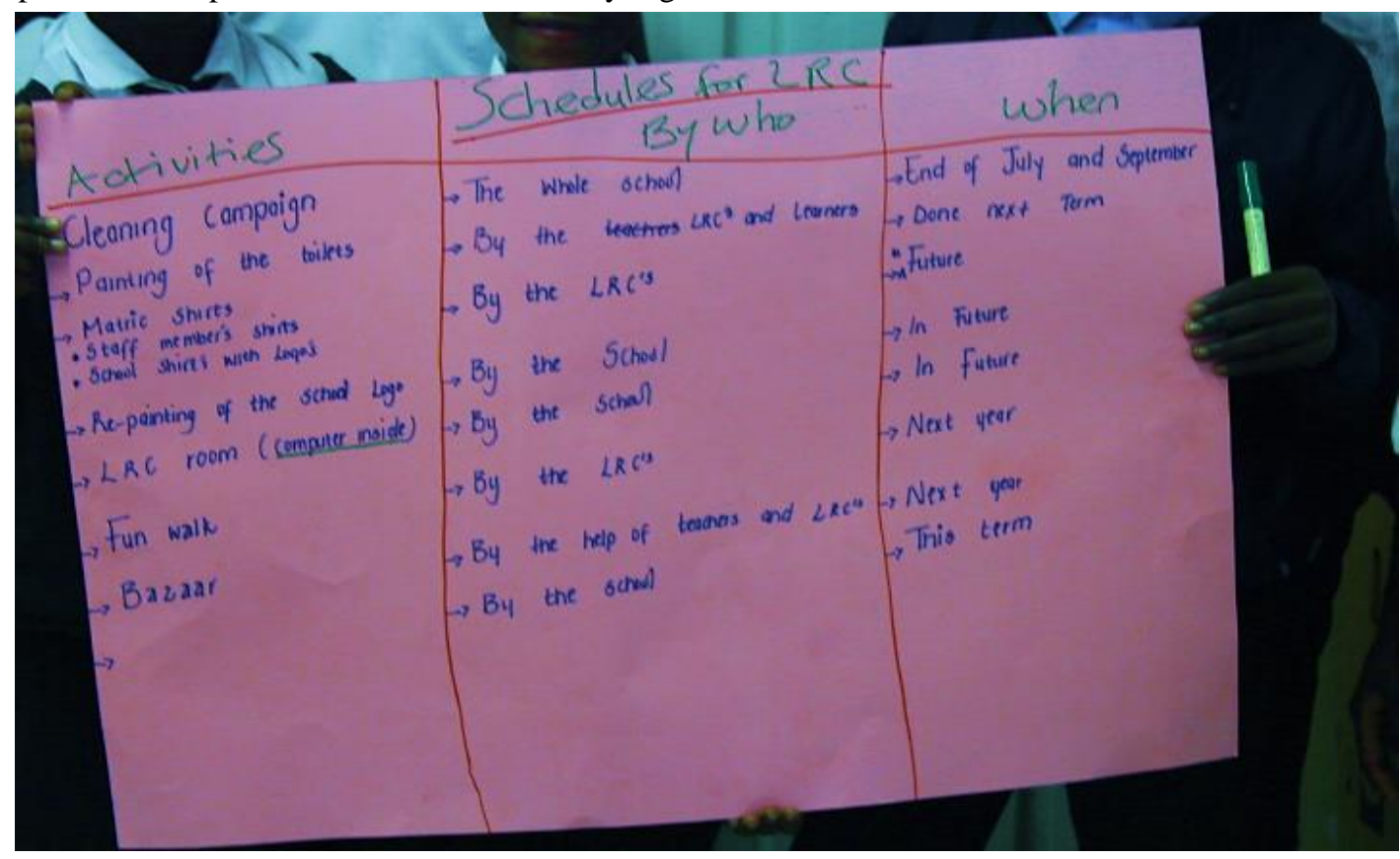

Figure 10: The poster with planned activities for the rest of the year

Overall, the change laboratory workshops provided an ideal opportunity for learner leaders to map out their leadership direction. All learner leaders need is support from different educational stakeholders to be able to realise their leadership aspirations.

\section{CONCLUSION}

The usage of CHAT was ideal for our study since it gave learners a platform through Change Laboratory workshops to voice out issues. Learners participated in discussions and decision- making during the Change Laboratory workshops and this resonates with the views of democratic education which is organised around participation in decision-making by all stakeholders, including learners. Therefore, CHAT is an ideal theoretical model to inform Change Laboratory workshops in facilitating the development and nurturing of LRC leadership, which might result in eliminating the silence in learner voice which is the focus of the study. We made specific choices for our research study, such as the usage of second generation CHAT and having the LRC members only in the CLWs. We argue that these choices were to do with giving learners the space to speak, since in the African context, had other stakeholders been there, the learners would not have voiced their opinions so openly.

\section{REFERENCES}

1) Berg, B. L. (2001). Qualitative research methods for social sciences (4 ${ }^{\text {th }}$ ed.). Boston: Allyn \& Bacon.

2) Berg, B. L. (2001). Qualitative research methods for social sciences ( $4^{\text {th }}$ ed.). Boston: Allyn \& Bacon.

3) Bertram, C., \& Christiansen, L. (2014). Understanding research: An introduction to reading research. Pretoria: Van Schaik Publishers.

4) Bolden, R. (2011). Distributed leadership in organizations: A review of theory and research. International Journal of Management Reviews, 13, 251-269.

5) Bowen, G. (2009). Document analysis as a qualitative research method. Qualitative Research Journal, 9(2), 27-40.

6) Chavez, C. (2008). Conceptualizing from inside: advantages, complications and demands on insider positionality. The Qualitative Report, 13(3), 474-494.

7) Cohen, L., Manion, L., \& Morrison, K. (2000). Research methods in Education (5 ${ }^{\text {th }}$ ed.). London: Routledge.

8) Cohen, L., Manion, L., \& Morrison, K. (2011). Research methods in education ( $7^{\text {th }}$ ed.). New York: Routledge.

9) Daniels, H. (2008). Vygotsky and research. London: Routledge Taylor \& Francis Group.

10) Drever, E. (1997). Using semi-structured interviews in small scale research: A teacher's guide. Glasgow: The Scottish Council for Research in Education.

11) Engeström, Y. (1987). Learning by expanding: An activity theoretical approach. Helsinki, Finland: Orienta-Konsultit.

12) Engeström, Y. (2001). Expansive learning at work: toward an activity theoretical reconceptualization. Journal of Education and Work, 14(1), 133-156.

13) Engeström, Y. (2016). Studies in expansive learning: Learning what is not yet there. New York: Cambridge Press. 


\section{Change Laboratory Workshops as Tools for Improving Learner Leadership in Schools: A Researcher-Interventionist}

Approach

14) Engeström, Y., \& Sannino, A. (2010). Studies of expansive learning: foundations, findings and future challenges. Educational Research Reviews, (5), 1-24.

15) Fielding, M. (2004). New wave student voice and renewal of civic society. London Review of Education, 2(3), 197-217.

16) Foot, K. A. (2001). Cultural-Historical Activity Theory as a practice theory: Illuminating the development of a conflictmonitoring network. International Communication Association, 11(1), 56-83.

17) Gay, L., Mills, G., \& Airasian, P. (2009). Educational research: competencies for analysis and applications. London: Pearson.

18) Grant, C. (2015). Invoking learners' voice and developing leadership: What matters to learners? Journal of Education, 61, 93-113.

19) Grant, C. (2017). Excavating the South African teacher leadership archive: Surfacing the absences and re-imagining the future. Educational Management Administration \& Leadership, 1-19.

20) Grant, C., \& Nekondo, L. (2016). Learners as leaders in Namibian schools: Taking responsibility and exercising agency. Namibia CPD Journal for Educators, 3(1), 13-29.

21) Hine, G. (2011). Exploring the development of student leadership potential within a catholic school: a qualitative case study. University of Notre Dame. Australia, Research online @ ND

22) Jacobs, A., \& Walker, S. (2014). Introduction to research in education ( $9^{\text {th }}$ ed.). Australia: Wadsworth Cengage learning.

23) Janesick, V. (1999). A journal about journaling: Writing as a qualitative research technique history issues and reflections. Qualitative Inquiry, 5(4), 505-524.

24) John. W. C. (2014). Educational research: Planning, conducting and evaluating quantitative and qualitative research ( $^{\text {th }}$ ed.). London: Pearson.

25) Johnson. B., \& Christensen. L. (2012). Educational research: quantitative, qualitative and mixed approaches. Los Angeles: Sage Publications.

26) Kamati, A. (2011). A study of code switching in Junior Secondary Physical Science classrooms in selected schools in the Oshana Education Region. Unpublished Master's thesis. University of Namibia, Windhoek.

27) Lichtman, M. (2014). Qualitative research for the social sciences. Los Angeles: Sage Publications.

28) Maree, K. (2007). First steps in research. Pretoria: Van Schaik Publishers.

29) Masilela, M. P. (2017). The development and institutionalisation of knowledge and knowledge sharing practices relating to the management of health risk waste in a home-based care setting. Unpublished Master's thesis. Rhodes University, Grahamstown.

30) Mason, J. (2002). Qualitative researching (2nd ed.). London: Sage Publications.

31) Merriam, S. (1998). Qualitative research and case study applications in education. San Francisco: Jossey-Bass.

32) Mitra, D. L., \& Gross, S. (2009). Increasing student in high school reform: Building partnership, improving outcomes. Educational Management Administration \& Leadership, 37(4), 522-543.

33) Mitra, D. L. (2007). Student voice in school reform: from listening to leadership. In D. Thiessen \& A. Cook-Sather (Eds.), International Handbook of student experience in elementary and secondary school (pp. 727-744). Dordrecht, Netherlands: Springer Publishers.

34) Mukute, M. (2010). Exploring and expanding learning processes in sustainable agriculture workplace contexts. Unpublished PhD thesis. Rhodes University, Grahamstown.

35) Namibia. Ministry of Basic Education, Sport and Culture. (2003). Language policy for schools in Namibia. Discussion Document. Windhoek: Government of the Republic of Namibia.

36) Nussbaumer, D. (2012). An overview of cultural historical activity theory (CHAT) use in classroom research 2000 to 2009. Journal of Educational Review, 64(1).

37) Olavarria, R. B. (2013). Using Cultural-Historical Activity Theory (CHAT) to study relationship between school leadership and organisational change. PHD Thesis. Queensland University of Technology, Queensland.

38) Ploettner, J., \& Tresseras, E. (2016). An interview with Yrjo Engeström and Anna Sannino on activity theory. Bellaterra Journal of Teaching and Learning Language and Literature, 9(4), 87-98.

39) Rule, P., \& John, V. (2011). Interpreting the case \& presenting the data: Your guide to case studies. Pretoria: Van Schaik Publishers.

40) Sannino, A. (2009). Teachers' talk of experiencing: conflict, resistance and agency. Teacher and Teacher Education, 26, 838-844.

41) Sannino, A. (2011). Activity theory as an activist and interventionist theory. Theory \& Psychology, 21(5), 571-597.

42) Sannino, A., Daniels, H., \& Gutierrez, K. D. (2009). Learning and expanding with activity theory. Cambridge: Cambridge University Press. 


\section{Change Laboratory Workshops as Tools for Improving Learner Leadership in Schools: A Researcher-Interventionist}

Approach

43) Sannino, A., Engeström, Y., \& Lemos, M. (2016). Formative interventions for expansive learning and transformative agency. Journal of the Learning Sciences, 25(4), 599-633.

44) Simons, H. (2009). Case study research in practice. London: SAGE Publications.

45) Thomas, G. (2009). How to do your research project. Los Angeles: Sage Publications.

46) Tötemeyer, A-J. (2010). Multilingualism and the language policy for Namibian schools. PRAESA Occasional papers NO.37. University of Cape Town.

47) Van der Mescht, H. (2002). Four levels of rigour in interpretive qualitative research. Education as Change, 6(1), 45-51.

48) Virkkunnen, J., \& Newnham, D. S. (2013). The change laboratory: A tool for collaborative development of work and education. Rotterdam: Sense Publishers.

49) Wassenaar, D. R. (2007). Ethical issues in social research. In M.T. Blanche, K. Durrheim, \& D. Painter (Eds.), Research in practice: Applied methods for social sciences ( $2^{\text {nd }}$ ed.) (pp. 60-79). Cape Town: University of Cape Town Press.

50) Yamagata-Lynch, L. (2010). Activity systems analysis methods: Understanding complex learning environments. New York: Springer Science: Business Media. 